\title{
Generalization of Mizoguchi-Takahashi type contraction and related fixed point theorems
}

\author{
Quanita Kiran ${ }^{1 *}$, Muhammad Usman Ali² and Tayyab Kamran ${ }^{2,3}$
}

\section{${ }^{*}$ Correspondence:}

quanita.kiran@seecs.nust.edu.pk

${ }^{1}$ School of Electrical Engineering and Computer Sciences, National

University of Sciences and

Technology, H-12, Islamabad,

Pakistan

Full list of author information is

available at the end of the article

\begin{abstract}
In this paper, we introduce a new notion to generalize a Mizoguchi-Takahashi type contraction. Then, using this notion, we obtain a fixed point theorem for multivalued maps. Our results generalize some results by Minak and Altun, Kamran and those contained therein.
\end{abstract}

MSC: $47 \mathrm{H} 10 ; 54 \mathrm{H} 25$

Keywords: Mizoguchi-Takahashi contraction; $\alpha$-admissible maps; $\alpha_{*}$-admissible maps

\section{Introduction and preliminaries}

The notions of $\alpha-\psi$-contractive and $\alpha$-admissible mappings were introduced by Samet et al. [1]. They proved some fixed point results for such mappings in complete metric spaces. These notions were generalized by Karapinar and Samet [2]. Asl et al. [3] extended these notions to multifunctions and introduced the notions of $\alpha_{*}-\psi$-contractive and $\alpha_{*}$-admissible mappings. Afterwards Ali and Kamran [4] further generalized the notion of $\alpha_{*}-\psi$-contractive mappings and obtained some fixed point theorems for multivalued mappings. Some interesting extensions of results by Samet et al. [1] are available in [5-13]. Nadler initiated a fixed point theorem for multivalued mappings. Some extensions of Nadler's result can also be found in [14-31]. Mizoguchi and Takahashi [32] extended the Nadler fixed point theorem. Recently, Minak and Altun generalized Mizoguchi and Takahashi's theorem by introducing a function $\alpha: X \times X \rightarrow[0, \infty)$. In this paper, we introduce the notion of $\alpha_{*}$-Mizoguchi-Takahashi type contraction. By using this notion, we generalize some fixed point theorems presented by Minak and Altun [7], Kamran [26] and those contained therein.

We denote by $C L(X)$ the class of all nonempty closed subsets of $X$ and by $C B(X)$ the class of all nonempty closed and bounded subsets of $X$. For $A \in C L(X)$ or $C B(X)$ and $x \in X$, $d(x, A)=\inf \{d(x, a): a \in A\}$, and $H$ is a generalized Hausdorff metric induced by $d$. Now we recollect some basic definitions and results for the sake of completeness.

If, for $x_{0} \in X$, there exists a sequence $\left\{x_{n}\right\}$ in $X$ such that $x_{n} \in T x_{n-1}$, then $O\left(T, x_{0}\right)=$ $\left\{x_{0}, x_{1}, x_{2}, \ldots\right\}$ is said to be an orbit of $T: X \rightarrow C L(X)$ at $x_{0}$. A mapping $h: X \rightarrow \mathbb{R}$ is said to be $T$-orbitally lower semicontinuous at $\xi \in X$, if $\left\{x_{n}\right\}$ is a sequence in $O\left(T, x_{0}\right)$ and $x_{n} \rightarrow \xi$ implies $h(\xi) \leq \liminf h\left(x_{n}\right)$. The following definition is due to Asl et al. [3]. 
Definition 1.1 [3] Let $(X, d)$ be a metric space, $\alpha: X \times X \rightarrow[0, \infty)$ and $T: X \rightarrow C L(X)$. Then $T$ is $\alpha_{*}$-admissible if for each $x, y \in X$ with $\alpha(x, y) \geq 1 \Rightarrow \alpha_{*}(T x, T y) \geq 1$, where $\alpha_{*}(T x, T y)=\inf \{\alpha(a, b): a \in T x, b \in T y\}$.

Minak and Altun [7] generalized Mizoguchi and Takahashi's theorem in the following way.

Theorem 1.2 [7] Let $(X, d)$ be a complete metric space, $T: X \rightarrow C B(X)$ be a mapping satisfying

$$
\alpha_{*}(T x, T y) H(T x, T y) \leq \phi(d(x, y)) d(x, y) \quad \text { for each } x, y \in X,
$$

where $\phi:[0, \infty) \rightarrow[0,1)$ such that $\lim _{\sup _{r \rightarrow t^{+}}} \phi(r)<1$ for each $t \in[0, \infty)$. Also assume that

(i) $T$ is $\alpha_{*}$-admissible;

(ii) there exists $x_{0} \in X$ with $\alpha\left(x_{0}, x_{1}\right) \geq 1$ for some $x_{1} \in T x_{0}$;

(iii) (a) $T$ is continuous,

or

(b) if $\left\{x_{n}\right\}$ is a sequence in $X$ with $x_{n} \rightarrow x$ as $n \rightarrow \infty$ and $\alpha\left(x_{n}, x_{n+1}\right) \geq 1$ for each $n \in \mathbb{N} \cup\{0\}$, then we have $\alpha\left(x_{n}, x\right) \geq 1$ for each $n \in \mathbb{N} \cup\{0\}$.

Then $T$ has a fixed point.

Kamran in [26] generalized Mizoguchi and Takahashi's theorem in the following way.

Theorem 1.3 [26] Let $(X, d)$ be a complete metric space and $T: X \rightarrow C L(X)$ be a mapping satisfying

$$
d(y, T y) \leq \phi(d(x, y)) d(x, y) \quad \text { for each } x \in X \text { and } y \in T x,
$$

where $\phi:[0, \infty) \rightarrow[0,1)$ such that $\limsup _{r \rightarrow t^{+}} \phi(r)<1$ for each $t \in[0, \infty)$. Then,

(i) for each $x_{0} \in X$, there exists an orbit $\left\{x_{n}\right\}$ of $T$ and $\xi \in X$ such that $\lim _{n} x_{n}=\xi$;

(ii) $\xi$ is a fixed point of $T$ if and only if the function $h(x):=d(x, T x)$ is $T$-orbitally lower semicontinuous at $\xi$.

\section{Main results}

We begin this section with the following definition.

Definition 2.1 Let $(X, d)$ be a metric space, $T: X \rightarrow C L(X)$ is said to be an $\alpha_{*}$-MizoguchiTakahashi type contraction if there exist two functions $\alpha: X \times X \rightarrow[0, \infty)$ and $\phi$ : $[0, \infty) \rightarrow[0,1)$ satisfying $\lim \sup _{r \rightarrow t^{+}} \phi(r)<1$ for every $t \in[0, \infty)$ such that

$$
\alpha_{*}(T x, T y) d(y, T y) \leq \phi(d(x, y)) d(x, y) \quad \text { for each } x \in X \text { and } y \in T x \text {. }
$$

Before moving toward our main results, we prove some lemmas.

Lemma 2.2 Let $(X, d)$ be a metric space, $\left\{A_{k}\right\}$ be a sequence in $C L(X),\left\{x_{k}\right\}$ be a sequence in $X$ such that $x_{k} \in A_{k-1}$. Let $\phi:[0, \infty) \rightarrow[0,1)$ be a function satisfying $\lim \sup _{r \rightarrow t^{+}} \phi(r)<1$ 
for every $t \in[0, \infty)$. Suppose that $\left\{d\left(x_{k-1}, x_{k}\right)\right\}$ is a nonincreasing sequence such that

$$
\begin{aligned}
& d\left(x_{k}, A_{k}\right) \leq \phi\left(d\left(x_{k-1}, x_{k}\right)\right) d\left(x_{k-1}, x_{k}\right), \\
& d\left(x_{k}, x_{k+1}\right) \leq d\left(x_{k}, A_{k}\right)+\phi^{n_{k}}\left(d\left(x_{k-1}, x_{k}\right)\right),
\end{aligned}
$$

where $n_{1}<n_{2}<\cdots, k, n_{k} \in \mathbb{N}$. Then $\left\{x_{k}\right\}$ is a Cauchy sequence in $X$.

Proof The proof runs on the same lines as the proof of [18, Lemma 3.2]. We include its details for completeness. Let $d_{k}:=d\left(x_{k-1}, x_{k}\right)$. Since $d_{k}$ is a nonincreasing sequence of nonnegative real numbers, therefore $\lim _{k \rightarrow \infty} d_{k}=c \geq 0$. By hypothesis, for $t=c$, we get $\lim \sup _{t \rightarrow c^{+}} \phi(t)<1$. Therefore, there exists $k_{0}$ such that $k \geq k_{0}$ implies that $\phi\left(d_{k}\right)<h$, where $\lim \sup _{t \rightarrow c^{+}} \phi(t) \leq h<1$. From (2.2) and (2.3), we have

$$
\begin{aligned}
d_{k+1} \leq & \phi\left(d_{k}\right) d_{k}+\phi^{n_{k}}\left(d_{k}\right) \\
\leq & \phi\left(d_{k}\right) \phi\left(d_{k-1}\right) d_{k-1}+\phi\left(d_{k}\right) \phi^{n_{k-1}}\left(d_{k-1}\right)+\phi^{n_{k}}\left(d_{k}\right) \\
& \ldots \\
\leq & \prod_{i=1}^{k} \phi\left(d_{i}\right) d_{1}+\sum_{m=1}^{k-1} \prod_{i=m+1}^{k} \phi\left(d_{i}\right) \phi^{n_{m}}\left(d_{m}\right)+\phi^{n_{k}}\left(d_{k}\right) \\
\leq & \prod_{i=1}^{k} \phi\left(d_{i}\right) d_{1}+\sum_{m=1}^{k-1} \prod_{i=\max \left\{k_{0}, m+1\right\}}^{k} \phi\left(d_{i}\right) \phi^{n_{m}}\left(d_{m}\right)+\phi^{n_{k}}\left(d_{k}\right) .
\end{aligned}
$$

We have deleted some factors of $\phi$ from the product in (2.4) using the fact that $\phi<1$. Let $S$ denote the second term on the right-hand side of (2.4),

$$
\begin{aligned}
S & \leq\left(k_{0}-1\right) h^{k-k_{0}+1} \sum_{m=1}^{k_{0}-1} \phi^{n_{m}}\left(d_{m}\right)+\sum_{m=k_{0}}^{k-1} h^{k-m} \phi^{n_{m}}\left(d_{m}\right) \\
& \leq\left(k_{0}-1\right) h^{k-k_{0}+1} \sum_{m=1}^{k_{0}-1} \phi^{n_{m}}\left(d_{m}\right)+\sum_{m=k_{0}}^{k-1} h^{k-m+n_{m}} \\
& \leq C h^{k}+\sum_{m=k_{0}}^{k-1} h^{k-m+n_{m}} \\
& \leq C h^{k}+h^{k+n_{k_{0}}-k_{0}}+h^{k+n_{k_{0}-1}-\left(k_{0}-1\right)}+\cdots+h^{k+n_{k-1}-(k-1)} \\
& \leq C h^{k}+\sum_{m=k+n_{k_{0}}-k_{0}}^{k+n_{k-1}-(k-1)} h^{m} \\
& =C h^{k}+\frac{h^{k+n_{k_{0}}-k_{0}+1}-h^{k+n_{k-1}-k+2}}{1-h} \\
& <C h^{k}+h^{k} \frac{h^{n_{k_{0}}-k_{0}+1}}{1-h} \\
& =C h^{k},
\end{aligned}
$$


where $C$ is a generic positive constant. Now, it follows from (2.4) that

$$
\begin{aligned}
d_{k+1} & \leq \prod_{i=1}^{k} \phi\left(d_{i}\right) d_{1}+C h^{k}+\phi^{n_{k}}\left(d_{k}\right) \\
& <h^{k-k_{0}+1} \prod_{i=1}^{k_{0}-1} \phi\left(d_{i}\right) d_{1}+C h^{k}+h^{n_{k}} \\
& <C h^{k}+C h^{k}+k \\
& =C h^{k},
\end{aligned}
$$

$C$ again being a generic constant. Now, for $k \geq k_{0}, m \in \mathbb{N}$,

$$
\begin{aligned}
d\left(x_{k}, x_{k+m}\right) & \leq \sum_{i=k+1}^{k+m} d_{i} \\
& <\sum_{i=k+1}^{k+m} C h^{i-1} \\
& =C \frac{h^{k+1}-h^{k+m}}{1-h} \\
& \leq h^{k},
\end{aligned}
$$

which shows that $\left\{x_{k}\right\}$ is a Cauchy sequence in $X$.

Lemma 2.3 Let $(X, d)$ be a metric space, $T: X \rightarrow C L(X)$ be an $\alpha_{*}$-Mizoguchi-Takahashi type contraction. Let $\left\{x_{k}\right\}$ be an orbit of $T$ at $x_{0}$ such that $\alpha_{*}\left(T x_{k-1}, T x_{k}\right) \geq 1$ and

$$
d\left(x_{k}, x_{k+1}\right) \leq d\left(x_{k}, T x_{k}\right)+\phi^{n_{k}}\left(d\left(x_{k-1}, x_{k}\right)\right)
$$

where $x_{k} \in T x_{k-1}, n_{1}<n_{2}<\cdots$ and $k, n_{k} \in \mathbb{N}$ and $\left\{d\left(x_{k-1}, x_{k}\right)\right\}$ is a nonincreasing sequence. Then $\left\{x_{k}\right\}$ is a Cauchy sequence in $X$.

Proof Given that $\left\{x_{k}\right\}$ is an orbit of $T$ at $x_{0}$, i.e., $x_{k} \in T x_{k-1}$ for each $k \in \mathbb{N}$, with $\alpha_{*}\left(T x_{k-1}, T x_{k}\right) \geq 1$ for each $k \in \mathbb{N}$, as $T$ is an $\alpha_{*}$-Mizoguchi-Takahashi type contraction. From (2.1), we have

$$
\begin{aligned}
d\left(x_{k}, T x_{k}\right) & \leq \alpha_{*}\left(T x_{k-1}, T x_{k}\right) d\left(x_{k}, T x_{k}\right) \\
& \leq \phi\left(d\left(x_{k-1}, x_{k}\right)\right) d\left(x_{k-1}, x_{k}\right) .
\end{aligned}
$$

From (2.5), we have

$$
d\left(x_{k}, x_{k+1}\right) \leq d\left(x_{k}, T x_{k}\right)+\phi^{n_{k}}\left(d\left(x_{k-1}, x_{k}\right)\right) \text {. }
$$

Since all the conditions of Lemma 2.2 are satisfied, $\left\{x_{k}\right\}$ is a Cauchy sequence in $X$.

Theorem 2.4 Let $(X, d)$ be a complete metric space, $T: X \rightarrow C L(X)$ be an $\alpha_{*}$-MizoguchiTakahashi type contraction and $\alpha_{*}$-admissible. Suppose that there exist $x_{0} \in X$ and $x_{1} \in$ Tx $x_{0}$ such that $\alpha\left(x_{0}, x_{1}\right) \geq 1$. Then, 
(i) there exists an orbit $\left\{x_{n}\right\}$ of $T$ and $x^{*} \in X$ such that $\lim x_{n}=x^{*}$;

(ii) $x^{*}$ is a fixed point of $T$ if and only if $h(x)=d(x, T x)$ is T-orbitally lower semicontinuous at $x^{*}$.

Proof By hypothesis, we have $x_{0} \in X$ and $x_{1} \in T x_{0}$ with $\alpha\left(x_{0}, x_{1}\right) \geq 1$. Thus, for $x_{1} \in T x_{0}$, we can choose a positive integer $n_{1}$ such that

$$
\phi^{n_{1}}\left(d\left(x_{0}, x_{1}\right)\right) \leq\left[1-\phi\left(d\left(x_{0}, x_{1}\right)\right)\right] d\left(x_{0}, x_{1}\right) .
$$

There exists $x_{2} \in T x_{1}$ such that

$$
d\left(x_{1}, x_{2}\right) \leq d\left(x_{1}, T x_{1}\right)+\phi^{n_{1}}\left(d\left(x_{0}, x_{1}\right)\right) .
$$

As $T$ is $\alpha_{*}$-admissible, we have $\alpha_{*}\left(T x_{0}, T x_{1}\right) \geq 1$. From (2.6) and (2.7) it follows that

$$
\begin{aligned}
d\left(x_{1}, x_{2}\right) & \leq d\left(x_{1}, T x_{1}\right)+\phi^{n_{1}}\left(d\left(x_{0}, x_{1}\right)\right) \\
& \leq \alpha_{*}\left(T x_{0}, T x_{1}\right) d\left(x_{1}, T x_{1}\right)+\phi^{n_{1}}\left(d\left(x_{0}, x_{1}\right)\right) \\
& \leq \phi\left(d\left(x_{0}, x_{1}\right)\right) d\left(x_{0}, x_{1}\right)+\left[1-\phi\left(d\left(x_{0}, x_{1}\right)\right)\right] d\left(x_{0}, x_{1}\right) \\
& =d\left(x_{0}, x_{1}\right) .
\end{aligned}
$$

Now we can choose a positive integer $n_{2}>n_{1}$ such that

$$
\phi^{n_{2}}\left(d\left(x_{1}, x_{2}\right)\right) \leq\left[1-\phi\left(d\left(x_{1}, x_{2}\right)\right)\right] d\left(x_{1}, x_{2}\right) .
$$

There exists $x_{3} \in T x_{2}$ such that

$$
d\left(x_{2}, x_{3}\right) \leq d\left(x_{2}, T x_{2}\right)+\phi^{n_{2}}\left(d\left(x_{1}, x_{2}\right)\right) .
$$

As $T$ is $\alpha_{*}$-admissible, then $\alpha\left(x_{1}, x_{2}\right) \geq \alpha_{*}\left(T x_{0}, T x_{1}\right) \geq 1$ implies $\alpha_{*}\left(T x_{1}, T x_{2}\right) \geq 1$. Using (2.8) and (2.9) we have that

$$
\begin{aligned}
d\left(x_{2}, x_{3}\right) & \leq d\left(x_{2}, T x_{2}\right)+\phi^{n_{2}}\left(d\left(x_{1}, x_{2}\right)\right) \\
& \leq \alpha_{*}\left(T x_{1}, T x_{2}\right) d\left(x_{2}, T x_{2}\right)+\phi^{n_{2}}\left(d\left(x_{1}, x_{2}\right)\right) \\
& \leq \phi\left(d\left(x_{1}, x_{2}\right)\right) d\left(x_{1}, x_{2}\right)+\left[1-\phi\left(d\left(x_{1}, x_{2}\right)\right)\right] d\left(x_{1}, x_{2}\right) \\
& =d\left(x_{1}, x_{2}\right) .
\end{aligned}
$$

By repeating this process for all $k \in \mathbb{N}$, we can choose a positive integer $n_{k}$ such that

$$
\phi^{n_{k}}\left(d\left(x_{k-1}, x_{k}\right)\right) \leq\left[1-\phi\left(d\left(x_{k-1}, x_{k}\right)\right)\right] d\left(x_{k-1}, x_{k}\right) .
$$

There exists $x_{k} \in T x_{k-1}$ such that

$$
d\left(x_{k}, x_{k+1}\right) \leq d\left(x_{k}, T x_{k}\right)+\phi^{n_{k}}\left(d\left(x_{k-1}, x_{k}\right)\right) .
$$


Also, by $\alpha_{*}$-admissibility of $T$, we have $\alpha_{*}\left(T x_{k-1}, T x_{k}\right) \geq 1$ for each $k \in \mathbb{N}$. From (2.10) and (2.11) it follows that

$$
\begin{aligned}
d\left(x_{k}, x_{k+1}\right) & \leq d\left(x_{k}, T x_{k}\right)+\phi^{n_{k}}\left(d\left(x_{k-1}, x_{k}\right)\right) \\
& \leq \alpha_{*}\left(T x_{k-1}, T x_{k}\right) d\left(x_{k}, T x_{k}\right)+\phi^{n_{k}}\left(d\left(x_{k-1}, x_{k}\right)\right) \\
& \leq \phi\left(d\left(x_{k-1}, x_{k}\right)\right) d\left(x_{k-1}, x_{k}\right)+\left[1-\phi\left(d\left(x_{k-1}, x_{k}\right)\right)\right] d\left(x_{k-1}, x_{k}\right) \\
& =d\left(x_{k-1}, x_{k}\right),
\end{aligned}
$$

which implies that $\left\{d\left(x_{k}, x_{k+1}\right)\right\}$ is a nonincreasing sequence of nonnegative real numbers. Thus, by Lemma 2.3, $\left\{x_{k}\right\}$ is a Cauchy sequence in $X$. Since $X$ is complete, there exists $x^{*} \in X$ such that $x_{k} \rightarrow x^{*}$ as $k \rightarrow \infty$. Since $x_{k} \in T x_{k-1}$, it follows from (2.1) that

$$
\begin{aligned}
d\left(x_{k}, T x_{k}\right) & \leq \alpha_{*}\left(T x_{k-1}, T x_{k}\right) d\left(x_{k}, T x_{k}\right) \\
& \leq \phi\left(d\left(x_{k-1}, x_{k}\right)\right) d\left(x_{k-1}, x_{k}\right) \\
& <d\left(x_{k-1}, x_{k}\right) .
\end{aligned}
$$

Letting $k \rightarrow \infty$, in the above inequality, we have

$$
\lim _{k \rightarrow \infty} d\left(x_{k}, T x_{k}\right)=0
$$

Suppose that $h(x)=d(x, T x)$ is $T$-orbitally lower semicontinuous at $x^{*}$, then

$$
d\left(x^{*}, T x^{*}\right)=h\left(x^{*}\right) \leq \liminf _{k} h\left(x_{k}\right)=\liminf _{k} d\left(x_{k}, T x_{k}\right)=0 .
$$

By the closedness of $T$ it follows that $x^{*} \in T x^{*}$. Conversely, suppose that $x^{*}$ is a fixed point of $T$, then $h\left(x^{*}\right)=0 \leq \liminf _{k} h\left(x_{k}\right)$.

Example 2.5 Let $X=\left\{\frac{1}{n}: n \in \mathbb{N}\right\} \cup\{0\} \cup(1, \infty)$ be endowed with the usual metric $d$. Define $T: X \rightarrow C L(X)$ by

$$
T x= \begin{cases}\{0\} & \text { if } x=0, \\ \left\{\frac{1}{n+2}, \frac{1}{n+3}\right\} & \text { if } x=\frac{1}{n}: 1 \leq n \leq 6, \\ \left\{\frac{1}{n}, 0\right\} & \text { if } x=\frac{1}{n}: n>6 \\ {[2 x, \infty)} & \text { if } x>1,\end{cases}
$$

and $\alpha: X \times X \rightarrow[0, \infty)$ by

$$
\alpha(x, y)= \begin{cases}1 & \text { if } x, y \in\left\{\frac{1}{n}: n \in \mathbb{N}\right\} \cup\{0\} \\ 0 & \text { otherwise }\end{cases}
$$

Define $\phi:[0, \infty) \rightarrow[0,1)$ by

$$
\phi(t)= \begin{cases}\frac{4}{5} & \text { if } 0 \leq t \leq \frac{1}{6} \\ \frac{1}{2} & \text { if } t>\frac{1}{6}\end{cases}
$$


One can check that for each $x \in X$ and $y \in T x$, we have

$$
\alpha_{*}(T x, T y) d(y, T y) \leq \phi(d(x, y)) d(x, y) .
$$

Also, $T$ is $\alpha_{*}$-admissible and for $x_{0}=1$ we have $x_{1}=\frac{1}{3} \in T x_{0}$ with $\alpha\left(x_{0}, x_{1}\right)=1$. Moreover, all the other conditions of Theorem 2.4 are satisfied. Therefore $T$ has a fixed point. Note that Theorem 5 of Minak and Altun [7] is not applicable here; see, for example, $x=\frac{1}{7}$ and $y=\frac{1}{8}$. Further Theorem 2.1 of Kamran [26] is also not applicable; see, for example, $x=2$ and $y=4 \in T x$.

The proofs of the following theorems run on the same lines as the proof of Theorem 2.4.

Theorem 2.6 Let $(X, d)$ be a complete metric space, $T: X \rightarrow C L(X)$ be an $\alpha_{*}$-admissible mapping such that

$$
\alpha_{*}(y, T y) d(y, T y) \leq \phi(d(x, y)) d(x, y) \quad \text { for each } x \in X \text { and } y \in T x
$$

where $\phi:[0, \infty) \rightarrow[0,1)$ satisfying limsup $\operatorname{sit}_{r+} \phi(r)<1$ for every $t \in[0, \infty)$. Suppose that there exist $x_{0} \in X$ and $x_{1} \in T x_{0}$ such that $\alpha\left(x_{0}, x_{1}\right) \geq 1$. Then,

(i) there exists an orbit $\left\{x_{n}\right\}$ of $T$ and $x^{*} \in X$ such that $\lim x_{n}=x^{*}$;

(ii) $x^{*}$ is a fixed point of $T$ if and only if $h(x)=d(x, T x)$ is T-orbitally lower semicontinuous at $x^{*}$.

Theorem 2.7 Let $(X, d)$ be a complete metric space, $T: X \rightarrow C L(X)$ be an $\alpha_{*}$-admissible mapping such that

$$
\alpha(x, y) d(y, T y) \leq \phi(d(x, y)) d(x, y) \quad \text { for each } x \in X \text { and } y \in T x,
$$

where $\phi:[0, \infty) \rightarrow[0,1)$ satisfying $\limsup _{r \rightarrow t^{+}} \phi(r)<1$ for every $t \in[0, \infty)$. Suppose that there exist $x_{0} \in X$ and $x_{1} \in T x_{0}$ such that $\alpha\left(x_{0}, x_{1}\right) \geq 1$. Then,

(i) there exists an orbit $\left\{x_{n}\right\}$ of $T$ and $x^{*} \in X$ such that $\lim x_{n}=x^{*}$;

(ii) $x^{*}$ is a fixed point of $T$ if and only if $h(x)=d(x, T x)$ is T-orbitally lower semicontinuous at $x^{*}$.

Corollary 2.8 [26] Let $(X, d)$ be a complete metric space and $T: X \rightarrow C L(X)$ be a mapping satisfying

$$
d(y, T y) \leq \phi(d(x, y)) d(x, y) \quad \text { for each } x \in X \text { and } y \in T x,
$$

where $\phi:[0, \infty) \rightarrow[0,1)$ such that $\limsup _{r \rightarrow t^{+}} \phi(r)<1$ for each $t \in[0, \infty)$. Then,

(i) for each $x_{0} \in X$, there exists an orbit $\left\{x_{n}\right\}$ of $T$ and $\xi \in X$ such that $\lim _{n} x_{n}=\xi$;

(ii) $\xi$ is a fixed point of $T$ if and only if the function $h(x):=d(x, T x)$ is T-orbitally lower semicontinuous at $\xi$.

Proof Define $\alpha: X \times X \rightarrow[0, \infty)$ by $\alpha(x, y)=1$ for each $x, y \in X$. Then the proof follows from Theorem 2.4 as well as from Theorem 2.6, and from Theorem 2.7. 


\section{Application}

From Definition 2.1, we get the following definition by considering only those $x \in X$ and $y \in T x$ for which we have $\alpha_{*}(T x, T y) \geq 1$.

Definition 3.1 Let $(X, d)$ be a metric space, $T: X \rightarrow C L(X)$ is said to be a modified $\alpha_{*}$-Mizoguchi-Takahashi type contraction if there exist two functions $\alpha: X \times X \rightarrow[0, \infty)$ and $\phi:[0, \infty) \rightarrow[0,1)$ satisfying lim $\sup _{r \rightarrow t^{+}} \phi(r)<1$ for every $t \in[0, \infty)$ such that for each $x \in X$ and $y \in T x$,

$$
\alpha_{*}(T x, T y) \geq 1 \quad \Rightarrow \quad d(y, T y) \leq \phi(d(x, y)) d(x, y) .
$$

Lemma 3.2 Let $(X, d)$ be a metric space, $T: X \rightarrow C L(X)$ be a modified $\alpha_{*}$-MizoguchiTakahashi contraction. Let $\left\{x_{k}\right\}$ be an orbit of $T$ at $x_{0}$ such that $\alpha_{*}\left(T x_{k-1}, T x_{k}\right) \geq 1$ and

$$
d\left(x_{k}, x_{k+1}\right) \leq d\left(x_{k}, T x_{k}\right)+\phi^{n_{k}}\left(d\left(x_{k-1}, x_{k}\right)\right)
$$

where $x_{k} \in T x_{k-1}, n_{1}<n_{2}<\cdots$ and $k, n_{k} \in \mathbb{N}$ and $\left\{d\left(x_{k-1}, x_{k}\right)\right\}$ is a nonincreasing sequence. Then $\left\{x_{k}\right\}$ is a Cauchy sequence in $X$.

Proof Given that $\left\{x_{k}\right\}$ is an orbit of $T$ at $x_{0}$, i.e., $x_{k} \in T x_{k-1}$ for each $k \in \mathbb{N}$, with $\alpha_{*}\left(T x_{k-1}, T x_{k}\right) \geq 1$ for each $k \in \mathbb{N}$, as $T$ is a modified $\alpha_{*}$-Mizoguchi-Takahashi contraction. From (3.1), we have

$$
d\left(x_{k}, T x_{k}\right) \leq \phi\left(d\left(x_{k-1}, x_{k}\right)\right) d\left(x_{k-1}, x_{k}\right) .
$$

From (3.2), we have

$$
d\left(x_{k}, x_{k+1}\right) \leq d\left(x_{k}, T x_{k}\right)+\phi^{n_{k}}\left(d\left(x_{k-1}, x_{k}\right)\right) .
$$

Since all the conditions of Lemma 2.2 are satisfied, $\left\{x_{k}\right\}$ is a Cauchy sequence in $X$.

Working on the same lines as the proof of Theorem 2.4 is done, one may obtain the proof of the following result.

Theorem 3.3 Let $(X, d)$ be a complete metric space, $T: X \rightarrow C L(X)$ be a modified $\alpha_{*}$-Mizoguchi-Takahashi contraction and $\alpha_{*}$-admissible. Suppose that there exist $x_{0} \in X$ and $x_{1} \in T x_{0}$ such that $\alpha\left(x_{0}, x_{1}\right) \geq 1$. Then,

(i) there exists an orbit $\left\{x_{n}\right\}$ of $T$ and $x^{*} \in X$ such that $\lim x_{n}=x^{*}$;

(ii) $x^{*}$ is a fixed point of $T$ if and only if $h(x)=d(x, T x)$ is T-orbitally lower semicontinuous at $x^{*}$. 


\section{Author details}

'School of Electrical Engineering and Computer Sciences, National University of Sciences and Technology, H-12, Islamabad, Pakistan. ${ }^{2}$ Department of Mathematics, School of Natural Sciences, National University of Sciences and Technology, H-12, Islamabad, Pakistan. ${ }^{3}$ Department of Mathematics, Quaid-i-azam University, Islamabad, Pakistan.

\section{Acknowledgements}

Authors are thankful to referees for their valuable suggestions.

\section{Received: 29 March 2014 Accepted: 1 September 2014 Published: 19 Nov 2014}

\section{References}

1. Samet, B, Vetro, C, Vetro, P: Fixed point theorems for $\alpha$ - $\psi$-contractive type mappings. Nonlinear Anal. 75, 2154-2165 (2012)

2. Karapınar, E, Samet, B: Generalized $\alpha$ - $\psi$-contractive type mappings and related fixed point theorems with applications. Abstr. Appl. Anal. 2012, Article ID 793486 (2012)

3. Asl, JH, Rezapour, S, Shahzad, N: On fixed points of $\alpha-\psi$-contractive multifunctions. Fixed Point Theory Appl. 2012, 212 (2012). doi:10.1186/1687-1812-2012-212

4. Ali, MU, Kamran, T: On $\left(\alpha^{*}, \psi\right)$-contractive multi-valued mappings. Fixed Point Theory Appl. 2013, 137 (2013). doi:10.1186/1687-1812-2013-137

5. Mohammadi, B, Rezapour, S, Shahzad, N: Some results on fixed points of $\alpha$ - $\psi$-Ciric generalized multifunctions. Fixed Point Theory Appl. 2013, 24 (2013). doi:10.1186/1687-1812-2013-24

6. Amiri, P, Rezapour, S, Shahzad, N: Fixed points of generalized $\alpha-\psi$-contractions. Rev. R. Acad. Cienc. Exactas Fís. Nat., Ser. A Mat. (2014). doi:10.1007/s13398-013-0123-9

7. Minak, G, Altun, I: Some new generalizations of Mizoguchi-Takahashi type fixed point theorem. J. Inequal. Appl. 2013, 493 (2013). doi:10.1186/1029-242X-2013-493

8. Salimi, P, Latif, A, Hussain, N: Modified $\alpha$ - $\psi$-contractive mappings with applications. Fixed Point Theory Appl. 2013, 151 (2013). doi:10.1186/1687-1812-2013-151

9. Hussain, N, Salimi, P, Latif, A: Fixed point results for single and set-valued $\alpha-\eta$ - $\psi$-contractive mappings. Fixed Point Theory Appl. 2013, 212 (2013). doi:10.1186/1687-1812-2013-212

10. Mohammadi, B, Rezapour, S: On modified $\alpha$ - $\varphi$-contractions. J. Adv. Math. Stud. 6, 162-166 (2013)

11. Ali, MU, Kamran, T, Karapınar, E: A new approach to $(\alpha, \psi)$-contractive nonself multivalued mappings. J. Inequal. Appl. 2014, 71 (2014). doi:10.1186/1029-242X-2014-71

12. Ali, MU, Kamran, T, Karapınar, E: $(\alpha, \psi, \xi)$-Contractive multi-valued mappings. Fixed Point Theory Appl. 2014,7 (2014) doi:10.1186/1687-1812-2014-7

13. Ali, MU, Kamran, T, Sintunavarat, W, Katchang, P: Mizoguchi-Takahashi's fixed point theorem with $\alpha, \eta$ functions Abstr. Appl. Anal. 2013, Article ID 418798 (2013)

14. Ali, MU: Mizoguchi-Takahashi's type common fixed point theorem. J. Egypt. Math. Soc. 22(2), 272-274 (2014)

15. Ali, MU, Kamran, T: Hybrid generalized contractions. Math. Sci. 7, 29 (2013). doi:10.1186/2251-7456-7-29

16. Damjanovica, B, Samet, B, Vetro, C: Common fixed point theorems for multivalued maps. Acta Math. Sci. 32, 818-824 (2012)

17. Kamran, T: Coincidence and fixed points for hybrid strict contractions. J. Math. Anal. Appl. 299, 235-241 (2004)

18. Kamran, T: Multi-valued $f$-weakly Picard mappings. Nonlinear Anal. 67, 2289-2296 (2007)

19. Kamran, T: Common coincidence points of R-weakly commuting maps. Int. J. Math. Math. Sci. 26, 179-182 (2001)

20. Shahzad, N, Kamran, T: Coincidence points and R-weakly commuting maps. Arch. Math. 37, 179-183 (2001)

21. Sintunavarat, $\mathrm{W}$, Kumam, $\mathrm{P}$ : Weak condition for generalized multi-valued $(f, \alpha, \beta)$-weak contraction mappings. Appl. Math. Lett. 24, 411-421 (2011)

22. Sintunavarat, W, Kumam, P: Coincidence and common fixed points for hybrid strict contractions without the weakly commuting condition. Appl. Math. Lett. 22, 1877-1881 (2009)

23. Sintunavarat, $W$, Kumam, P, Patthanangkoor, P: Common random fixed points for multivalued random operators without S- and T-weakly commuting random operators. Random Oper. Stoch. Equ. 17, 381-388 (2009)

24. Samet, B, Vetro, C: Comment on the paper 'Coincidence theorems for some multivalued mappings' by B.E. Rhoades, S.L. Singh and C. Kulshrestha. Fasc. Math. 47, 89-94 (2011)

25. Khan, AR, Akbar, F, Sultana, N, Hussain, N: Coincidence and invariant approximation theorems for generalized f-nonexpansive multivalued mappings. Int. J. Math. Math. Sci. 2006, Article ID 17637 (2006)

26. Kamran, T: Mizoguchi-Takahashi's type fixed point theorem. Comput. Math. Appl. 57, $507-511$ (2009)

27. Haghi, RH, Rezapour, S, Shahzad, N: Some fixed point generalization are not real generalizations. Nonlinear Anal. 74, 1799-1803 (2011)

28. Sintunavarat, W, Kumam, P: Common fixed point theorems for hybrid generalized multi-valued contraction mappings. Appl. Math. Lett. 25(1), 52-57 (2012)

29. Sintunavarat, W, Kumam, P: Common fixed point theorem for cyclic generalized multi-valued contraction mappings. Appl. Math. Lett. 25(11), 1849-1855 (2012)

30. Kumam, P, Aydi, H, Karapınar, E, Sintunavarat, W: Best proximity points and extension of Mizoguchi-Takahashi's fixed point theorems. Fixed Point Theory Appl. 2013, 242 (2013)

31. Sintunavarat, W, Lee, DM, Cho, YJ: Mizoguchi-Takahashi's type common fixed point theorems without T-weakly commuting condition and invariant approximations. Fixed Point Theory Appl. 2014, 112 (2014)

32. Mizoguchi, N, Takahashi, W: Fixed point theorems for multivalued mappings on complete metric spaces. J. Math. Anal. Appl. 141, 177-188 (1989)

\subsection{6/1029-242X-2014-458}

Cite this article as: Kiran et al.: Generalization of Mizoguchi-Takahashi type contraction and related fixed point theorems. Journal of Inequalities and Applications 2014, 2014:458 